\title{
NOTE ON THE INDIVIDUALITIES OF ANHYDROFRUCTOSE AND DIFRUCTOSE ANHYDRIDE
}

\author{
By R. F. Jackson and S. M. Goergen
}

\section{ABSTRACT}

Almost simultaneously with the publication of Research Paper No. 79 of the Bureau of Standards in which is described a crystalline difructose anhydride, Irvine and Stevenson published a description of a new anhydrofructose. These two substances showed such similar physical properties as to suggest their identity. It is now shown that difructose anhydride has a different molecular weight and melting point from anhydrofructose. The two substances are, therefore, not identical.

In the course of an investigation ${ }^{1}$ of the hydrolysis of inulin by sulphuric acid in aqueous solution, the authors isolated a group of nonreducing disaccharides, one of which was obtained in crystalline form and shown to be a difructose anhydride.

Almost simultaneously with the release of this article Irvine and Stevenson ${ }^{2}$ published a description of a crystalline anhydrofructose which they isolated in 20 per cent yield from inulin. The striking similarity in physical properties between these two sugars raises the question whether they are not identical. The respective properties previously published are shown in the following table:

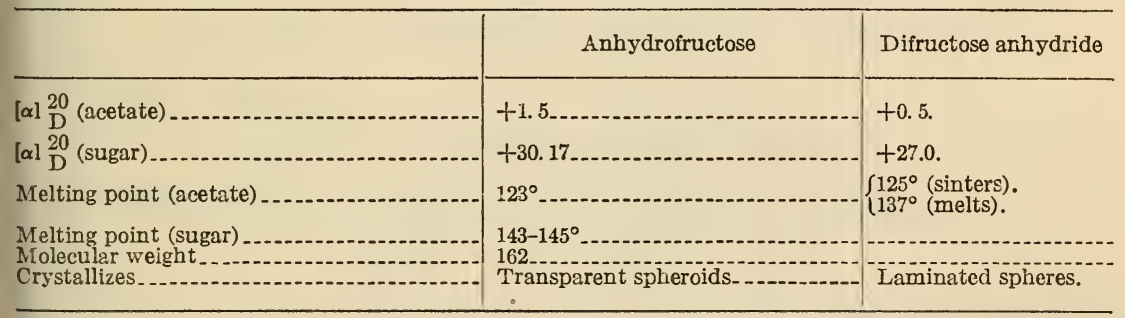

An important difference is the behavior of the respective sugars when exposed to air. Anhydrofructose is deliquescent, while difructose anhydride remains dry even in an atmosphere of high humidity. The latter will even crystallize from aqueous solutions when evaporating in open vessels at room temperature.

In our study of difructose anhydride we had isolated it in the form of its hexa-acetate. The determination of the molecular weight of the acetate by measurement of the depression of freezing point of

\footnotetext{
1 B. S. Jour. Research, 3, p. 27; 1929. (RP 79.)

2 J. Am. Chem. Soc., 51, p. 2197; 1929.
} 
benzene showed so definitely that it was the acetate of a disaccharide that we deemed it unnecessary to determine the molecular weight of the free sugar. In order, however, to differentiate conclusively between this sugar and the anhydrofructose of Irvine and Stevenson, we have determined the molecular weight and melting point of difructose anhydride. Mol. wt., Subs., 1.0103; water, 20.298; $\Delta T, 0.307^{\circ}$. Mol. wt., calcd., 324 ; found, 307. Mpt., $162-164^{\circ}$. There is therefore no question of the individualities of these respective sugars.

Washington, June 14, 1930. 